\title{
REVIEW
}

\section{Application of forensic techniques to enhance fish conservation and management: injury detection using presumptive tests for blood}

\author{
Alison H. Colotelo ${ }^{1, *}$, Steven J. Cooke ${ }^{1}$, Karen E. Smokorowski ${ }^{2}$ \\ ${ }^{1}$ Fish Ecology and Conservation Physiology Laboratory, Department of Biology \& Institute of Environmental Science, \\ Carleton University, Ottawa, Ontario K1S 5B6, Canada \\ ${ }^{2}$ Great Lakes Laboratory for Fisheries and Aquatic Sciences, Fisheries and Oceans Canada, 1 Canal Drive, \\ Sault Ste. Marie, Ontario P6A 6W4, Canada
}

\begin{abstract}
The detection of injury on the skin of fish has generally been limited to gross macroscopic examination, which has numerous limitations, including researcher subjectivity and a lack of quantitative analytical capacity. The use of chemical enhancers, such as those used by forensic analysts, can aid in the detection and quantification of skin injuries in fish, which can arise from fish interactions with humans and anthropogenic infrastructure (e.g. recreational and commercial fishing, research sampling, fishway passage or guidance, turbines). In this review, we examine several presumptive tests for blood and evaluate their potential usefulness for detecting and quantifying injury in fish. Our evaluation was based on sensitivity, specificity, cost, carcinogenicity and ease of use. Fluorescein and Bluestar ${ }^{\circledR}$ offer the ability to perform whole body detection, but require low-light conditions and a digital camera to capture the emitted light. Several tests (i.e. Hemastix ${ }^{\circledR}$, Hemident $^{\mathrm{TM}}$, phenolphthalein) yield rapid results and do not require large or expensive pieces of equipment, which makes them ideal for field use, although further research is needed to validate these tools for use on different fish species and in different contexts. Collectively, these tools show promise for a variety of fish research, conservation and management applications, including hydropower assessment, commercial fisheries bycatch evaluation, and analysis of the practices and gear regulations associated with recreational angling.
\end{abstract}

KEY WORDS: Blood $\cdot$ Conservation science $\cdot$ Fish monitoring $\cdot$ Forensic techniques $\cdot$ Injury detection Resale or republication not permitted without written consent of the publisher

\section{INTRODUCTION}

Forensic techniques encompass those procedures employed during crime scene analysis by identification officers and forensic scientists. Increasingly, these tools are being applied to conservation-related research and monitoring. Most notably, forensic techniques based on molecular genetics have been used in wildlife management cases, in which the animal poached is often visually unidentifiable, making it difficult to distinguish a threatened or protected species from a legal kill. DNA analysis can help identify the species in question, as well as help link an individual to the scene of the infraction (Wan \& Fang 2003). Likewise, forensic genetic tools have been used to identify the illegal international trade of protected wildlife tissues (e.g. sturgeon and paddlefish caviar [Ludwig 2006]; sea turtles [Bowen \& Avise 1996]). However, there are many other underutilized tools in the field of wildlife forensics that have the potential to contribute to animal conservation and management, especially with regards to fish.

Presumptive tests for blood utilize a variety of chemicals to identify the presence of blood through a reaction with the haemoglobin molecule (Spalding 2006). 
They are described as presumptive because there are substances other than haemoglobin which may cause a false positive reaction, and in forensic settings further testing is required to confirm the result. These are rapid tests that are used to identify whether an unknown substance is likely blood and to identify areas of a crime scene that should be investigated in more detail. The benefit of utilizing these tests is the rapidity of results and the ease of interpretation.

Presumptive tests for blood show promise for documenting injury to fish that have interacted with humans or anthropogenic infrastructure. For example, hydroelectric dams (including fishway facilities and guidance technologies) and irrigation intakes are potentially a cause of external injuries for fish interacting with the infrastructure (Cada 1990). Similarly, when fish are discarded as bycatch in the commercial fishing sector, or through catch-and-release practices (voluntary or mandatory) in the recreational fishing sector, they can be exposed to dermal injuries from fishing line, hooks, nets and handling (e.g. Davis 2002, Barthel et al. 2003). Although basic capture techniques, such as the use of pot traps for the enumeration of fish, may appear to be benign, research has revealed that fish can experience significant abrasion and scale loss during the holding and handling processes (Cooke et al. 1998). Even minor abrasions to the skin of fish can increase the incidence of infection by opportunistic pathogens such as Saprolegnia spp. (Van West 2006), which could lead to delayed mortality or alterations in fish health and stress levels. There is now a suite of tools available for evaluating the physiological condition of fish in the field (summarized in Iwama et al. 1995), yet there are comparatively fewer tools available for detecting and quantifying physical injury. Quantifying the extent and severity of sub-lethal injuries is important for determining the consequences of human interactions with fish, and for developing strategies and/or infrastructure to reduce such injuries and promote fish welfare, which is currently becoming of increasing concern (Huntingford et al. 2006).

The objective of the present paper is to review a suite of presumptive tests for blood used in forensic analysis, and to identify their potential applicability to fish conservation and management. Such tests are necessary, as existing approaches for quantifying the sub-lethal injury of fish are qualitative and rely on crude indicators such as visual inspection of fin fraying (e.g. Barthel et al. 2003), scale loss (e.g. Chopin \& Arimoto 1995) and macroscopic wounds (e.g. Davis 2002). Only in recent years have forensic tools been applied in a fisheries context to investigate epithelial injury. In this review, we first summarize the use and basis of presumptive tests in forensic science, and then briefly discuss the integument, scales and mucus present on fish and reveal the associated challenges of using presumptive tests. Next, we summarize the various presumptive tests that have been developed and provide an overview of their actual or potential utility for research or monitoring of fish. We conclude by discussing how these presumptive tests have or could be applied to address a range of fish conservation and management problems and identify key research needs.

\section{PRESUMPTIVE TESTS: PREMISE AND USES IN FORENSIC SCIENCE}

Often at crime scenes there are stains composed of unknown substances that may be confused with blood. Identifying whether the substance is indeed blood allows further analyses to confirm species, and, if necessary, the individual (Spalding 2006). Alternatively, if blood was cleaned in an attempt to remove evidence, chemical enhancers are required to detect whether blood is present (even in miniscule amounts) and/or visualize any patterns (Spalding 2006). Presumptive tests are used to initially identify areas of high priority in crime scene investigation, and substances are later confirmed to be blood through microscopic tests (Spalding 2006). Presumptive tests have also been used in biomedical applications. For example, fluorescein, a common chemical for blood pattern visualization, has been adopted in ophthalmology to stain the corneal epithelium and identify lesions on the outer surface of the eye (Göbbels \& Spitnaz 1989). Although presumptive tests for blood are currently used primarily in a human context, the composition of blood is highly conserved among vertebrates, making these tests theoretically useful for fish. Furthermore, the epithelium of fish has been compared to the composition of the human cornea (Noga \& Udomkusonsri 2002), and so the use of fluorescein in corneal lesions appears to indicate the potential for use in fish epithelial lesions.

Regardless of the taxa being investigated, there are 2 basic concepts that are important when comparing presumptive tests for blood, namely, sensitivity and specificity. Sensitivity refers to the lowest dilution of blood that can be detected (Cox 1991), and is typically tested in a laboratory with blood samples diluted with distilled water (Tobe et al. 2007). The most sensitive presumptive blood test is luminol, with a recorded sensitivity of 1:1 000000 (Proescher \& Moody 1939), allowing the potential detection of a miniscule amount of blood. The majority of presumptive tests have a sensitivity of 1:100 000 (Tobe et al. 2007), although, depending on the surface tested and the preparation methods, sensitivity can vary. For all of the tests outlined in this review, the sensitivity is such that they have the ability to detect blood that would not be identified by gross macroscopic examination alone. 
Specificity refers to the ability of the chemical to accurately detect blood and identify substances that may present false positives or false negatives. Substances that may be visually mistaken for blood, or those that contain oxidizing agents (such as peroxidases), are tested as potential sources of false positives (Tobe et al. 2007). Generally, those substances that produce false positives take detectably longer to react and, therefore, may be eliminated through observational interpretation (Tobe et al. 2007). There is limited information in the forensic literature about false negatives, as it is difficult to prove that a false negative reaction has occurred (Ponce \& Pascual 1999). It is thought that reduction compounds compete for oxygen in oxidation-reduction reactions and are thus capable of causing false negative reactions.

In the comparison of presumptive tests for blood in a forensic context, a number of surface types are tested (e.g. carpet, cotton, linoleum). For example, Dilbeck (2006) compared luminol and Bluestar ${ }^{\circledR}$ on 4 different surfaces and revealed that surface material influenced their chemiluminescence strength. In the context of fish research, fish skin is a surface on which there has been very little comparative work related to presumptive tests for blood. It is therefore imperative to review the characteristics of fish skin and mucus, and their potential impact on the results and applicability of different forensic tools.

\section{FISH SKIN CHARACTERISTICS}

Vertebrate skin is the largest organ of the integument system and consists of multiple layers of epithelial tissue, acting as a barrier protecting the internal structures from the external environment. Skin structure is based on the vertebrate's environment and therefore can vary drastically, especially among taxa (Flaxman 1972). Fish are unique from other vertebrates as the living cells of the integument are in close proximity to the ambient environment (Hawkes 1974). Other vertebrates have a layer of keratinized cells which protect the living tissue from the environment (Flaxman 1972), which, for fish, is done by the mucus layer. Fish mucus consists of glycoproteins or mucins and a high concentration of water and is produced by goblet cells present in the epidermal tissue, particularly those located in the gills (Shephard 1994). The role of fish mucus is to protect the fish from dermal abrasion, disease and infection, to provide lubrication within water, and to aid in ion and osmotic homeostasis. Removal of the protective layer of mucus and underlying epidermis can result in opportunistic pathogenic infection and even death. The dynamic nature of fish mucus and its ability to be non-lethally sampled makes it a promising material to test for blood using presumptive tests.

\section{CHALLENGES OF USING PRESUMPTIVE TESTS FOR BLOOD ON FISH}

The use of forensic presumptive tests for blood in a fish context poses a number of challenges, including the unknown effect of the aquatic environment that may interfere with the correct interpretation of results. Although most presumptive tests for blood cannot distinguish between human and animal blood, there have not been any extensive studies on the sensitivity or specificity of these tests with respect to fish blood, particularly due to the unique substances present in an aquatic environment. Smith \& Ramos (1976) tested the sensitivity of Hemastix ${ }^{\circledR}$ for haemoglobin taken from butterfly fish Chaetodon miliaris, and they found strong positive reactions for dilutions of up to 1 part haemoglobin to 4 parts fish mucus. There is a need to investigate the sensitivity of these tests to enable accurate interpretation of the results.

In forensic science, substances that may potentially cause false positive reactions are generally substances that resemble blood or contain similar properties to blood and may be found at a crime scene. Substances that have been tested and may cause false positives in some trials include tomatoes, red kidney beans, horseradish and saliva (Tobe et al. 2007). There may be substances that are common to aquatic settings or fish that have not been investigated for their potential to cause false positive reactions, and therefore further research is necessary. Even less is known about the causes of false negatives, and investigations into the potential sources of error are necessary.

In addition to the environmental and physiological limitations involving the use of presumptive tests for blood on fish, each test presents its own set of benefits and limitations. The decision as to which tests should be further evaluated is based on the context of the research and the monitoring of fish condition and injury. The detection of haemoglobin in fish mucus is a non-lethal sampling procedure that can be conducted quickly to minimize the amount of time the fish is removed from its natural environment. There may also be reasons to employ these techniques in a laboratory situation or on dead fish.

\section{OVERVIEW OF PRESUMPTIVE TESTS FOR BLOOD}

Since many forensic tests have yet to be applied to research on fish, we provide an overview of the different presumptive tests for blood, discuss their actual or potential use on fish, and summarize their limitations and advantages. We base our assessment of potential fisheries applicability on a suite of 'ideal' characteristics. 
An ideal presumptive test on fish for blood would:

- produce rapid, robust and repeatable results which can be quantified;

- be environmentally safe to use directly on fish and in natural environments;

- require little personal protective equipment for the user;

- have a low cost, enabling repeated sampling;

- be easy to use in field settings without cumbersome equipment;

- have few interfering compounds.

\section{Catalytic colour tests}

Catalytic colour tests characterize the largest group of presumptive tests for blood available to researchers. These tests react with the heme group in blood, specifically by chemically oxidizing the chromogen, to produce a visible colour reaction. An oxidizing agent must be added to catalyze the reaction, generally hydrogen peroxide. A colour change characteristic of the chromogen that appears within seconds constitutes a positive reaction (Spalding 2006). All of the prescribed indicators have a reported sensitivity of at least a 1:10 000 dilution of human blood, but can be as high as 1:100000 (Tobe et al. 2007). The most commonly known catalytic colour tests are benzidine, o-toluidine, tetramethylbenzidine, phenolphthalein, leuchomalachite green, Hemident ${ }^{\mathrm{TM}}$ and Hemastix ${ }^{\circledR}$. Table 1 pro- vides a summary of these tests and their potential applicability in fish research, but most have carcinogenic or other properties that eliminate their potential for use in fish research. The only catalytic colour tests that show potential practical application in fish research are phenolphthalein, Hemastix ${ }^{\circledR}$ and Hemident $^{\mathrm{TM}}$, which will be explored further.

\section{Phenolphthalein (Kastle-Meyer test)}

The Kastle-Meyer test is one of the most common presumptive tests used in forensic laboratories. It uses reduced phenolphthalein in alkaline solution. A positive reaction is denoted by a colour change of colourless to pink and is immediate (Spalding 2006). This test is one of the most sensitive catalytic colour tests (1:10000), although false positive reactions have been documented for substances, including $1 \mathrm{M}$ ascorbic acid (Tobe et al. 2007). Phenolphthalein is listed by the International Agency for Research on Cancer (IARC) as a possible carcinogen to humans, and the agency has declared that there is sufficient evidence to support that phenolphthalein is carcinogenic to animals (IARC 2000). Therefore, there is a potential source of harm to the researcher. However, safety measures (e.g. wearing personal protective equipment) can be implemented, which would decrease these risks (Phenolphthalein Material Safety Data Sheet 2005; www. sciencelab.com/msds.php?msdsId=9926469).

Table 1. Summary of presumptive tests for blood and the applicability in fish research. Class 1: known carcinogens to humans; Class 2A: probable carcinogens to humans; Class 2B: possible carcinogens to humans; TMB: tetramethylbenzidine; NA: not available

\begin{tabular}{|c|c|c|c|c|c|c|c|}
\hline Test & Sensitivity & $\begin{array}{l}\text { Price } \\
\text { (\$CAD) }\end{array}$ & Carcinogen & $\begin{array}{l}\text { Tested } \\
\text { on fish }\end{array}$ & $\begin{array}{l}\text { Potential } \\
\text { field use }\end{array}$ & $\begin{array}{l}\text { Potential } \\
\text { lab use }\end{array}$ & Rationale \\
\hline Benzidine & 1:100000 & NA & Yes & No & None & None & $\begin{array}{l}\text { Class I carcinogen } \\
\text { (IARC 1987) }\end{array}$ \\
\hline o-Toluidine & $1: 100000$ & $\$ 32.95 / \mathrm{kit}$ & Yes & No & None & None & $\begin{array}{l}\text { Class 2A carcinogen } \\
\text { (IARC 1972) }\end{array}$ \\
\hline Phenolphthalein & 1:10000 & $\$ 34.00 /$ kit & Possible & No & Medium & High & $\begin{array}{l}\text { Class 2B carcinogen } \\
\text { (IARC 2000) }\end{array}$ \\
\hline $\begin{array}{l}\text { Leuchomalachite } \\
\text { green }\end{array}$ & $1: 10000$ & NA & Yes & Yes & None & None & $\begin{array}{l}\text { Hazardous to fish and humans } \\
\text { (Fessard et al. 1999) }\end{array}$ \\
\hline TMB & $1: 10000$ & $\$ 36.00 /$ kit & No & No & Low & Low & Hemastix ${ }^{\circledR}$ contain the reagent \\
\hline Hemastix ${ }^{\circledR}$ & $1: 100000$ & $\$ 35.00 / 50$ strips & No & No & High & High & $\begin{array}{l}\text { Easy to use; test strips are } \\
\text { pre-treated with reagent }\end{array}$ \\
\hline Hemident $^{\mathrm{TM}}$ & $1: 10000$ & $\$ 16.65 / 10$ tests & No & No & High & High & $\begin{array}{l}\text { Easy to use; self contained } \\
\text { reaction }\end{array}$ \\
\hline Fluorescein & $1: 100,000$ & $\$ 36.50 / 250 \mathrm{ml}$ & No & Yes & High & High & $\begin{array}{l}\text { Has already been tested and } \\
\text { used on fish for injury detection }\end{array}$ \\
\hline Luminol & $1: 1,000,000$ & $\$ 18.25 / 236 \mathrm{ml}$ & No & No & Low & Low & $\begin{array}{l}\text { Reaction only lasts } 30 \mathrm{~s} \text {; more } \\
\text { applicable methods available }\end{array}$ \\
\hline Bluestar $\left.^{(}\right)$ & 1:100000 & $\$ 89.00 / 500 \mathrm{ml}$ & No & No & Medium & High & $\begin{array}{l}\text { Easier to use than luminol; reac- } \\
\text { tion lasts longer and is brighter }\end{array}$ \\
\hline
\end{tabular}




\section{Hemastix ${ }^{\circledR}$}

Hemastix ${ }^{\circledR}$ were designed to detect blood in urine (for biomedical and veterinary applications), but have been adopted by the forensic community to test stains of unknown origin (Spalding 2006). Hemastix ${ }^{\circledR}$ are unique in their application and design. The kit contains test strips with reagent-treated filter paper attached to one end. The pre-treated filtered paper contains the reagent tetramethylbenzidine (TMB), along with all other chemicals required for the analysis (Tetramethylbenzidine Material Safety Data Sheet 2005; www.sciencelab.com/msds.php?msdsId= 9925220). This allows ease of use, and the materials required for this test are minimal and readily available. The manufacturer supplies a scale corresponding to the amount of human haemoglobin in each sample based on the colour change, but generally a positive reaction is illustrated by a colour change from yellow to green (Spalding 2006). Hemastix ${ }^{\circledR}$ have a reported sensitivity of 1:100 000, although different users report different sensitivities (Tobe et al. 2007). Also, there have been substances reported to cause false positives, including $10 \%$ cupric sulphate and $10 \%$ ferric sulphate (Tobe et al. 2007). Cupric sulphate would be a potential false positive for fish injury detection, as it is a known aquatic algaecide that is commonly used in aquaculture (Schlenk et al. 1998).

\section{Hemident $^{\mathrm{TM}}$}

Hemident $^{\mathrm{TM}}$ was created in 1981 for the purpose of aiding in criminal investigations (Spalding 2006). The reagent is MacPhail's reagent (leuchomalachite green), which was previously used as a fungal treatment for infected fish until its carcinogenic nature was revealed (Culp et al. 1999). Hemident ${ }^{\mathrm{TM}}$ is a selfcontained chemical reaction, and so the hazards to the user are limited. The instructions and all materials needed for correct use of this test are provided by the manufacturer. The benefit of this test is that the container can be kept and brought back to a laboratory, where further testing can be done if required (Tobe et al. 2007). Another highlight is that this test was designed for field use, and so its simplicity and ease of use are beneficial to fisheries scientists. All that is required for sampling fish mucus is a swab from a pre-selected area of the fish. The tested sensitivity for Hemident ${ }^{\mathrm{TM}}$ has been recorded as 1:10000 for blood (animal or human) (Tobe et al. 2007). With regards to specificity, there are no reported substances that stimulate a valid false positive reaction (Tobe et al. 2007).

\section{Fluorescence and chemiluminescence tests}

Fluorescence and chemiluminescence tests are typically used in situations where it is suspected that blood was once present and has subsequently been cleaned up (Spalding 2006), and they are used in liquid form for crime scene investigation. Chemical solutions are sprayed over the area, and, if blood is present, the bloodstain pattern will become evident through the production of light by either luminescence or fluorescence (Spalding 2006). This light can be detected visually and can be photographed for further reference and for quantification and localization of injury.

\section{Fluorescein}

Fluorescein is a commonly used presumptive test for blood for large areas and/or areas where no blood is present visually. It reacts with haemoglobin, similarly to the catalytic colour tests, but the reaction is based on the production of light (Tobe et al. 2007). Fluorescein is prepared by reducing it in an alkaline solution and then applying it to the test area. Hydrogen peroxide is then applied to accelerate the oxidation of the heme group. Under ultraviolet light (UV) the reaction will fluoresce at 520 to $530 \mathrm{~nm}$ and can be photographed. This test requires an alternate light source (ALS), typically set at $450 \mathrm{~nm}$, as well as a yellow filter for photography. The photography of the sample must be completed in a lowor no-light environment, which poses issues for field usage (Spalding 2006). The sensitivity of fluorescein has been reported as 1:100000, and there are some substances that may cause false positives, including copper and hypochlorite (Tobe et al. 2007).

This test has previously been used to detect physical injury in fish in a laboratory setting and showed promising results (Noga \& Udomkusonsri 2002). The study used the rainbow trout Oncorhynchus mykiss, channel catfish Ictalurus punctatus, goldfish Carassius auratus and hybrid striped bass Morone saxatilis male $\times M$. chrysops female). Fish were intentionally injured by removal of skin using a scalpel and by acute confinement, or by puncture with a needle. Fish were then euthanized and were completely submerged in the solution with the visible injuries photographed under UV light. Although fluorescein is documented as an irritant (Fluorescein Material Safety Data Sheet 2005; www.sciencelab.com/xMSDS-Fluorescein-9927171), there did not seem to be any adverse effects to live hybrid striped bass tested in high concentrations (Noga \& Udomkusonsri 2002), although this may be species-specific.

The use of fluorescein to detect fish injury has been applied in commercial fishery bycatch studies. Davis \& 
Ottmar (2006) used fluorescein to analyze the injury patterns in fish that were dragged in a net during a laboratory experiment meant to simulate commercial fishing practices. The proportion of the body surface injured from the experiment was examined using computer analysis software. Results of the afore-mentioned study showed a link between mortality and the proportion of abrasion for walleye pollock Theragra chalcogramma, but not for other species examined.

\section{Luminol}

Luminol, like fluorescein, is another blood detection chemical that produces light as a positive reaction. However, the production of light is through luminescence, not fluorescence, and does not require an ALS (Barni et al. 2007). The reaction occurs when the alkaline solution is sprayed over a test area, followed by an oxidizing agent. The reaction is best observed in a light-absent room and can be photographed, albeit the reaction only lasts for $30 \mathrm{~s}$ (Barni et al. 2007). Luminol is regarded as one of the most sensitive presumptive blood tests. Proescher \& Moody (1939) claimed that luminol could detect blood at a dilution of 1:10 000000 , although the sensitivity depends on the preparation method.

Luminol has been used previously on trout, to identify areas of injury on the skin and to the gills associated with recreational angling (Dedual \& Shorland 2006). The fish mucus had to be removed to conduct this test (using a damp cloth), because it is believed that the mucus creates a barrier between the blood and the luminol. This poses issues for sampling of fish using this product, since removal of the mucus would also potentially injure the epithelium, which is what is being detected using the test. It would therefore be difficult to distinguish between injury caused by the treatment and injury caused by the mucus removal. As well, the removal of the mucus from fish epithelium puts the fish at risk of infection, which can lead to stress and potentially to mortality after release.

\section{Bluestar ${ }^{\circledR}$}

Bluestar $^{\circledR}$ is the newest presumptive test for blood. It is based on the chemical formula for luminol, but has been altered to increase its ease of use (Barni et al. 2007). Bluestar ${ }^{\circledR}$ produces a positive result through luminescence; however, the reaction lasts longer than that of luminol and does not require complete darkness (Tobe et al. 2007). The reported sensitivity is 1:10 000, although laboratory tests have shown a sensitivity of 1:100 000 (Tobe et al. 2007). Literature from the manufacturer claims that false positives are easily identified by an experienced eye based on colour, duration and intensity of the light production. However, Tobe et al. (2007) report false positives on a number of substances, including tomatoes, bleach and $1 \mathrm{M}$ ascorbic acid. A further benefit of Bluestar ${ }^{\odot}$ is the ease of preparation, which involves the addition of 2 Bluestar@ tablets to a prescribed amount of water (Dilbeck 2006), eliminating any complicated chemical processes prior to field use. The prepared solution can be kept for weeks, in contrast to luminol, which must be mixed moments prior to each use. Bluestar ${ }^{\circledR}$ is highly basic, and so its potential uses may be limited to dead fish (Bluestar ${ }^{\circledR}$ Material Safety Data Sheet 2005; www.bluestar-forensic.com/pdf/en/ MSDS_tablets_working_solution.pdf).

\section{DISCUSSION}

While some presumptive tests for blood have been applied to fish, there is potential that more of these tests may be applicable in fish health assessments and research. Fluorescein and luminol have been used to enhance patterns of injury on a variety of fish species (Noga \& Udomkusonsri 2002, Dedual \& Shorland 2006), although these only proved to be helpful in visualizing injury patterns. Indeed, Dedual \& Shorland (2006) published photographs of the illuminated (and thus injured) regions in a fishing magazine to provide a dramatic illustration for anglers on how poor handling practices can affect fish health. Bluestar ${ }^{\circledR}$ should also be investigated for use on dead fish, as it has been shown to be favoured over luminol in forensic science (Dilbeck 2006). Digital photographs of the fluoresceinand Bluestar ${ }^{\circledR}$-treated fish can be analyzed using computer software to determine the percentage of area covered by haemoglobin (Davis \& Ottmar 2006, Dauble et al. 2007). None of the catalytic colour tests have been previously used in the context of enhancing injury patterns, although Hemastix ${ }^{\circledR}$ have been used to show early signs of stress in fish (Smith \& Ramos 1976). Phenolphthalein is regarded as a very specific presumptive test and should be investigated for potential field and laboratory use on fish.

Although we have outlined which tests appear to have the greatest potential application in fish research, further testing is required. All of the tests have been evaluated for sensitivity with respect to human blood; however, it is unknown whether blood from fish or other animals will yield different results. Testing of sensitivity for fish blood can be done by using diluted blood samples, as shown in Tobe et al. (2007), but dilution should be done using fish mucus to achieve accurate sensitivity measurements. The minimum concen- 
tration of haemoglobin necessary for a positive reaction can then be determined.

The specificity of the presumptive tests should not change when comparing human and animal blood; however, the aquatic environment contains possible contaminants that may cause false positive reactions that have not been explored in forensic science research, including biological peroxidises. Before these tests can be accurately applied in fish biology or research, investigations of possible causes of false positives should be completed. False negatives also should not change when comparing human and animal blood. One substance that has already been found to inhibit the fluorescence of fluorescein is tricaine (Davis et al. 2008). Tricaine is a commonly used fish anaesthesic, so when utilizing fluorescein other anaesthesics are necessary.

Identification of the most valuable presumptive tests for use in fish injury research would require controlled experimentation to determine which tests perform most accurately. As in Noga \& Udomkusonsri (2002), fish should be anesthetized and then inflicted with injuries commonly experienced, such as scale loss, abrasion and pinpoint ulcerations. The selected methods should then be compared. Furthermore, a comparison between the 2 methods of detection (catalytic colour vs. fluorescence and luminescence) should be conducted, to identify the benefits and limitations. Catalytic colour tests should be done by swabbing a selected area of mucus and applying reagents to the swab. Swabs from multiple pre-selected areas of the fish may help to outline general patterns of injury. Fluorescein, luminol and Bluestar ${ }^{\circledR}$ will require spraying or complete submersion of the fish in the appropriate solution. Digital photographs of these fish can be analyzed using computer software, to show the proportion of injury based on the proportion of the fish that is emitting a specific wavelength of light (i.e. 520 to $530 \mathrm{~nm}$ for fluorescein). Fluorescein and Bluestar ${ }^{\complement}$ could be used to test swabs of fish mucus; however, this would eliminate the capability to use digital analysis to quantify the proportion of injury. In all instances, confirmation of lesions should be completed using histology.

The goal of these evaluations will be to identify tests that could be used in both laboratory and field settings, which will also require an assessment of the safety of these chemicals to fish. A safety assessment has already been done for fluorescein for hybrid striped bass (Noga \& Udomkusonsri 2002), and similar methods could be used for luminol and Bluestar ${ }^{\circledR}$. Since the catalytic colour tests do not come into contact with the fish, these chemicals do not pose a direct threat to the fish. Nonetheless, for all tests, it would be valuable to determine if there are any sub-lethal or lethal consequences from any of the chemicals or procedures needed to quantify injury. This could be done through telemetry (to evaluate behavioural impairments or post-release mortality; Donaldson et al. 2008), reflex assessment for predicting delayed mortality (Davis \& Ottmar 2006), or holding fish for a period of time and monitoring delayed mortality.

A general assumption in fish injury assessments is that increased injury results in increased stress and threat to fish survival. The identification of presumptive tests for blood that can assist in quantifying the area of injury on fish would stimulate further research linking external injury to the physiological and behavioural responses, as well as delayed mortality due to injury. Physiological responses to adverse conditions can be investigated by non-lethal blood sampling and testing for a number of biomolecules, including cortisol, aspartate aminotransferase and lactate dehydrogenase (Grizzle et al. 1992, Wendelaar Bonga 1997).

\section{POTENTIAL APPLICATION TO FISH CONSERVATION AND MANAGEMENT}

Presumptive tests for blood show potential for use in fish conservation, including use in assessing sub-lethal injury from interaction with hydropower infrastructure, recreational and commercial fishing, research and handling, and general health monitoring. Before using these tests in fish conservation and management, limitations related to result confirmation apply and must be eliminated or validated as described above. However, once validated, these tools could become a simple component of routine fish monitoring when there is interest in documenting injuries to fish that arise from various human or non-human interactions.

\section{Hydropower}

Hydropower structures can have numerous effects on fish and the aquatic environment. Hydropower infrastructure often creates an impassable physical barrier, which most notably alters fish movement (e.g. Cada 2001). Several solutions for upstream fish passage have been implemented, including the installation of fishways, or trapping fish and physically moving them around the dam (Gowans et al. 1999). To date, no study has focused on the possible physical damage caused by hydropower infrastructure during upstream migration, although such studies would aid in the conservation and management of especially fragile species.

Non-migratory and migratory fish travelling downstream are also at risk of physical damage from hydroelectric dams. Entrainment is avoided through the use of fish screens and dam bypass structures, while down- 
stream fish passage is often facilitated by the installation of 'fish friendly' turbines. Passage through the hydroelectric turbines has been documented as a significant cause of mortality and physical damage (Cada 1990). Generally, the injury assessments of fish that pass through turbines are made by visual inspection, which at best can detect gross-scale injuries and trauma. The use of fluorescent or chemiluminescent presumptive tests would be able to help identify patterns of injury resulting from turbine passage, especially at the cellular level, which would likely be overlooked using visual inspection and has been linked to the behaviour and physiology of sub-lethally injured fish (Davis 2002). Catalytic colour tests would also be useful in locating the areas of the skin injured by turbine passage through sampling of pre-selected areas.

Fluorescein has already been used to assess injury in salmonids passing through a turbine. It was helpful in quantifying the injury (using computer software analysis), as well as in determining the types of injury (Dauble et al. 2007). The researchers found this method to be highly efficient, as it did not cause any more injury than would have occurred through visual assessments of anaesthetized fish, and fish could be released back into the water after the experiment was complete.

Fish residing downstream of dams or passing through dams can also be subjected to gas bubble disease (from pressure changes and/or gas supersaturation; Weitkamp \& Katz 1980). One of the signs of gas bubble disease is haemorrhaging from skin and fins, which could be quantified using forensic techniques.

\section{Recreational and commercial fishing}

Recreational and commercial fishing are practised on a global scale and involve the capture of billions of fish annually (Cooke \& Cowx 2004). One of the current concerns surrounding recreational fishing is the biological impact this has on individual fish. In some areas, catchand-release angling is widely practised, but the fates of those released fish are often unknown (Cooke \& Cowx 2004). As with the gas bubble disease issues described above for hydropower facilities, fish captured from deep water can suffer from similar symptoms. A recent study of smallmouth bass Micropterus dolomieu used qualitative metrics (presence and absence of reddened tissue indicating haemorrhaging) to characterize barotrauma incidences at a fishing tournament (Gravel \& Cooke 2008). The use of presumptive tests for blood in the assessments of barotrauma could provide more robust and reliable estimates of injuries resulting from fish being captured from deep water.
In commercial fisheries, bycatch can be a significant proportion of the total catch, and individual fish are released due to species, size, quantity, or sex (Davis 2002). The post-release (discard) mortality of these individuals has been linked to wounding, measured using fluorescein in a laboratory setting (Davis \& Ottmar 2006), and techniques exist to assess whether released fish will survive (Davis 2002). The evaluation of other methods of injury detection would be useful in both recreational and commercial fisheries, especially in relation to gear and handling method comparison. New techniques and equipment could be compared to standard practices for injury and associated delayed mortality.

\section{Research and handling}

Research often involves confinement and handling of fish, including containment in trap nets, hoop nets, live pot traps and holding tanks (Chopin \& Arimoto 1995). The effects of this equipment on injury, physiology, behaviour and survival are largely unknown. Cooke et al. (1998) performed post-mortem examinations to study the injuries on greenside darters Etheostoma blenniodes resulting from live pot traps. They observed scale loss and abrasions around the caudal area, which resulted in fungal growth and the eventual death of $74 \%$ of the fish, but quantifying injury would have been helpful in this investigation. The testing of all capture and confinement methods would be beneficial to identify those techniques with the least negative impacts on fish in order to maintain their condition and enhance survival.

Research involving individual fish almost always requires some form of handling. Handling is also an issue in catch-and-release angling, as fish are often held during hook removal, measurement and photography (Cooke \& Cowx 2004). Previous research demonstrated that fish held for a longer period of time have higher rates of post-release mortality (Pickering et al. 1982, Schramm et al. 1987). Handling can cause significant damage to fish, and has been documented using luminol and fluorescein (Noga \& Udomkusonsri 2002, Dedual \& Shorland 2006). Noga \& Udomkusonsri (2002) detected injuries that were not a result of the experimentally induced injury and concluded that these came from the handling of the fish during the experiment. Safe handling practices have been suggested for use by anglers and researchers, but visualizations of the injuries and quantifications of the extent of the trauma could aid in developing a standard protocol for fish handling and emphasize the negative consequences of poor handling. 


\section{General health monitoring}

A technique that could rapidly assess the general health and injury level of fish without being a hazard to the fish or environment would be ideal and would provide valuable information. Areas that would benefit from these rapid techniques for health assessment, for example, include aquaculture endeavours and other areas in which there is interest in minimizing injury from handling. This is particularly relevant when using hatcheries to enhance endangered fish populations. Obviously, any methods used on potential food-fish would need to be screened for their human impacts.

\section{CONCLUSION}

Assessment of non-visible injury in fish has rarely been conducted. Typically, macroscopic visual examination is used to identify injuries, but this approach is subjective and based on the severity of the trauma detectable to the naked eye. In the current paper, we presented an alternative approach to identifying and quantifying fish injury through blood detection techniques used in forensic science. The identification of a relevant and robust presumptive test for blood on fish would benefit many areas of fisheries research, including assessing the impacts of hydropower infrastructure, evaluating recreational and commercial fisheries, enhancing handling practices, and performing general health assessments. Collectively, such data should facilitate the conservation of a wide range of fish species.

Acknowledgements. This work was supported by Fisheries and Oceans Canada and Natural Resources Canada. Additional support was provided by the Ontario Ministry of Research and Innovation through the Early Researcher Award Program. We thank C. Hasler and other members of the Cooke Lab for providing detailed input on earlier versions of this manuscript. Research permits were provided by the Ontario Ministry of Natural Resources, and animal care approvals were granted by Carleton University and Queen's University on behalf of the Canadian Council for Animal Care.

\section{LITERATURE CITED}

Barni F, Lewis SW, Berti A, Miskelly GM, Lago G (2007) Forensic application of the luminol reaction as a presumptive test for latent blood detection. Talanta 72:896-913

Barthel BL, Cooke SJ, Suski CD, Philipp DP (2003) Effects of landing net mesh type on injury and mortality in a freshwater recreational fishery. Fish Res 63:275-282

Bowen BW, Avise JC (1996) Conservation genetics of marine turtles. In: Avise JC, Hamrick JL (eds) Conservation genetics: case histories from nature. Chapman \& Hall, New York, p 190-237
Cada G (1990) A review of studies relating to the effects of propeller-type turbine passage on fish early life stages. $\mathrm{N}$ Am J Fish Manag 10:418-426

Cada GF (2001) The development of advanced hydroelectric turbines to improve fish passage survival. Fisheries 26 : $14-24$

Chopin FS, Arimoto T (1995) The condition of fish escaping from fishing gears - a review. Fish Res 21:315-327

Cooke SJ, Cowx G (2004) The role of recreational fishing in global fish crises. Bioscience 54:857-859

> Cooke SJ, Bunt CM, McKinley S (1998) Injury and short term mortality of benthic stream fishes - a comparison of collection techniques. Hydrobiologia 379:207-211

> Cox M (1991) A study of the sensitivity and specificity of four presumptive tests for blood. J Forensic Sci 36:1503-1511

Culp SJ, Blankenship LR, Kusewitt DF, Doerge DR, Mulligan LT, Beland FA (1999) Toxicity and metabolism of malachite green and leucomalachite green during short-term feeding to Fischer 344 rats and B6C3F1 mice. Chem Biol Interact 122:153-170

Dauble DD, Deng ZD, Richmond MC, Moursund RA, Carlson TJ, Rakowski CL, Duncan JP (2007) Biological assessment of the advanced turbine design at Wanapum Dam, 2005. Prepared for the US Department of Energy, Office of Energy Efficiency and Renewable Energy, Wind and Hydropower Technologies, under Contract DE-AC0576RL01830, Richland, WA

Davis MW (2002) Key principles for understanding fish bycatch discard mortality. Can J Fish Aquat Sci 59: $1834-1843$

> Davis MW, Ottmar ML (2006) Wounding and reflex impairment may be predictors for mortality in discarded or escaped fish. Fish Res 82:1-6

Davis MW, Stephenson S, Noga EJ (2008) The effect of tricaine on use of the fluorescein test for detecting skin and corneal ulcers in fish. J Aquat Anim Health 20: 86-95

Dedual M, Shorland J (2006) Poor handling affects released trout. Target Taupo 52:5-13

Dilbeck L (2006) Use of Bluestar forensic in lieu of luminol at crime scenes. J Forensic Ident 56:706-720

Donaldson MR, Arlinghaus R, Hanson KC, Cooke SJ (2008) Enhancing catch-and-release science with biotelemetry. Fish Fish 9:79-105

Fessard V, Godard T, Huet S, Mourot A, Poul JM (1999) Mutagenicity of malachite green and leucomalachite green in in vitro tests. J Appl Toxicol 19:421-430

Flaxman BA (1972) Cell differentiation and its control in the vertebrate epidermis. Am Zool 12:13-25

Göbbels M, Spitnaz M (1989) Influence of artificial tears on corneal epithelium in dry-eye syndrome. Graefes Arch Clin Exp Ophthalmol 227:139-141

> Gowans ARD, Armstrong JD, Priede IG (1999) Movements of adult Atlantic salmon in relation to a hydroelectric dam and fish ladder. J Fish Biol 54:713-726

> Gravel MA, Cooke SJ (2008) Severity of barotrauma influences the physiological status, post-release behaviour, and fate of tournament-caught smallmouth bass. N Am J Fish Manag 28:607-617

Grizzle JM, Chen J, Williams JC, Spano JS (1992) Skin injuries and serum enzyme activities of channel catfish (Ictalurus punctatus) harvested by fish pumps. Aquaculture 107:333-346

Hawkes JW (1974) The structure of fish skin. Cell Tiss Res 149:147-158

Huntingford FA, Adams C, Braithwaite VA, Kadri S, Pottinger TG, Sandøe P, Turnbull JF (2006) Current issues in fish welfare. J Fish Biol 68:332-372 
IARC (International Agency for Research on Cancer) (1972) Some inorganic substances, chlorinated hydrocarbons, aromatic amines, N-nitroso compounds and natural products. IARC Monogr Eval Carcinog Risks Hum 1:94-97

IARC (International Agency for Research on Cancer) (1987) Overall evaluations of carcinogenicity: an updating of IARC Monographs Volumes 1 to 42. IARC Monogr Eval Carcinog Risks Hum Suppl 7:123-125

IARC (International Agency for Research on Cancer) (2000) Some antiviral and antineoplastic drugs, and other pharmaceutical agents. IARC Monogr Eval Carcinog Risks Hum 76:387-415

Iwama GK, Morgan JD, Barton BA (1995) Simple methods for monitoring stress and general condition of fish. Aquacult Res 26:273-282

Ludwig A (2006) A sturgeon view on conservation genetics. Eur J Wildl Res 52:3-8

Noga EJ, Udomkusonsri P (2002) Fluorescein: a rapid, sensitive, nonlethal method for detecting skin ulceration in fish. Vet Pathol 39:726-731

Pickering AD, Pottinger TG, Christie P (1982) Recovery of the brown trout, Salmo trutta L., from acute handling stress: a time-course study. J Fish Biol 20:229-244

Ponce AC, Pascual AV (1999) Critical revision of presumptive tests for bloodstains. US Department of Justice, Federal Bureau of Investigation, Washington, DC. www.fbi.gov/ hq/lab/fsc/backissu/july1999/ponce.htm

Proescher F, Moody AM (1939) Detection of blood by means of chemiluminescence. J Lab Clin Med 24:1183-1189

Schlenk D, Gollon JL, Griffin BR (1998) Efficacy of copper sul-

Editorial responsibility: Andrew Cunningham,

London, UK fate for the treatment of ichthyophthiriasis in channel catfish. J Aquat Anim Health 10:390-396

Schramm HL, Haydt PJ, Portier KM (1987) Evaluation of prerelease, postrelease, and total mortality of largemouth bass caught during tournaments in two Florida lakes. N Am J Fish Manag 7:394-402

Shephard KL (1994) Functions for fish mucus. Rev Fish Biol Fish 4:401-429

Smith AC, Ramos F (1976) Occult haemoglobin in fish skin mucus as an indicator of early stress. J Fish Biol 9: $537-541$

Spalding RP (2006) The identification and characterization of blood and bloodstains. In: James SH, Nordby JJ (eds) Forensic science: an introduction to scientific and investigative techniques, 2nd edn. CRC Press, Boca Raton, FL, p 237-260

Tobe SS, Watson N, Daéid NN (2007) Evaluation of six presumptive tests for blood, their specificity, sensitivity, and effect on high molecular-weight DNA. J Forensic Sci 52: 102-109

Van West P (2006) Saprolegnia parasitica, an oomycete pathogen with a fishy appetite: new challenges for an old problem. Mycologist 20:99-104

Wan QH, Fang SG (2003) Application of species-specific polymerase chain reaction in the forensic identification of tiger species. Forensic Sci Int 131:75-78

> Weitkamp DE, Katz M (1980) A review of dissolved gas supersaturation literature. Trans Am Fish Soc 109:659-702

> Wendelaar Bonga SE (1997) The stress response in fish. Physiol Rev 77:591-625

Submitted: April 18, 2008; Accepted: November 27, 2008 Proofs received from author(s): March 18, 2009 